\title{
SUPERVIVENCIA O DESAPARICION DE LOS INDIGENAS DE CARTAGENA DE INDIAS EN EL SIGLO XVII: EL SERVICIO PERSONAL A DEBATE CON EL GOBERNADOR MURGA
}

\author{
Julián B. Ruiz Rivera \\ Universidad de Sevilla
}

\begin{abstract}
Durante la larga presencia de España en América pocos temas ocuparon mayor atención de las autoridades que el trato dispensado a los indios y lo relacionado con el servicio personal, ${ }^{1}$ que si por un lado prueba la limitada eficacia de la legislación, por otro demuestra la incansable preocupación de los gobernantes por las poblaciones más indefensas. En este trabajo se aborda la situación del servicio personal en Cartagena durante el primer tercio del siglo XVII y la condición en que se hallaban los indios, lo mismo que el debate provocado en la provincia por una real cédula enviada al gobernador, Francisco de Murga.
\end{abstract}

\section{EL SERVICIO PERSONAL EN SUS COMIENZOS Y SU IMPACTO EN CARTAGENA}

El servicio personal fue la forma dominante de tributación de los indios en los comienzos de la colonización que en un principio se identificó con el traba-

José de Bartasa y Muñoz de Bustillo, El servicio personal de los indios durante la colonización española en América, Madrid, Revista de Archivos, Bibliotecas y Museos, 1925. 
jo minero. ${ }^{2}$ Luego se extendió a otras modalidades hasta verse obligado el emperador a prohibirlo por cédula de 22 de febrero de 1549. En México, por ejemplo, "hasta 1564 la población indígena no pagó tributos en dinero ni en bienes materiales a las autoridades españolas, sino que sus únicas obligaciones tributarias eran prestar servicio laboral". ${ }^{4}$

Existen categorías de servicio personal en la agricultura, la ganadería, la minería, los obrajes, el transporte, la construcción y, sobre todo, el trabajo doméstico, pero no debe confundirse con el repartimiento, porque este último se realizaba de manera obligatoria por turnos y de forma remunerada." La Recopilación recoge en el título XJJ del libro $6^{\circ}$ lo relativo al servicio personal, con intención de evitar los abusos. Hubo abundantísimas disposiciones que no fueron recogidas en la Recopilación, algunas de las cuales seleccionó Richard Konetzke para su colección documental, ${ }^{6}$ y más abundantemente lleva recopilando Silvio Zavala, tanto para el Perú como para Nueva España.

Las primeras encomiendas del Perú cobraban el tributo en servicio personal, que costó grandes esfuerzos erradicar incluso cuando ya se hallaban tasadas en tributos pecuniarios o en especie..$^{8}$ La instrucción al virrey Velasco en $1595^{9}$ ponía de manifiesto los abusos que particulares y autoridades civiles y religiosas originaban a los indios, si bien sólo hacía desaparecer los servicios personales en las encomiendas de nueva concesión. Para eliminar toda prestación laboral forzosa con excepción de la mita minera, se envió una real instrucción el 24 de noviembre de 1601 sobre el trabajo de los indios, que debía servir para detectar el grado de aceptación o de rechazo de la nueva política. ${ }^{10}$ A propósito de esta cédula un fraile franciscano escribió en un tratado sobre el servicio personal, exponiendo que contaba con grandes dificultades para erradicarse, dada la variedad de campos de actividad en que se utilizaba." Sin embargo, no se consiguió el acuerdo para erradi-

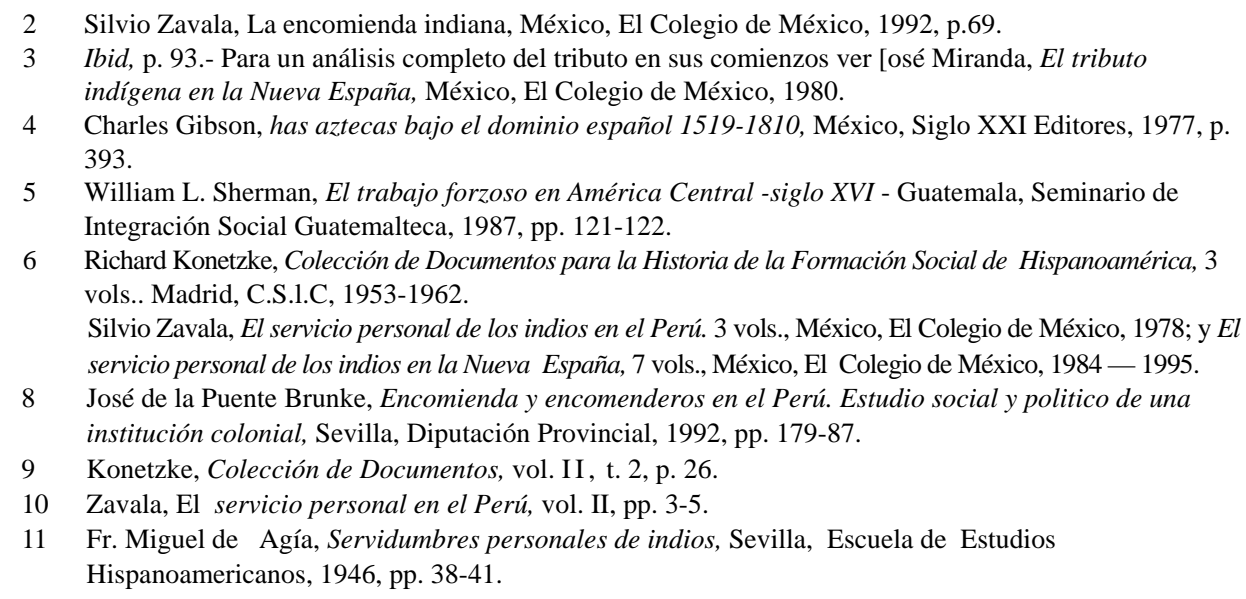


car el trabajo obligatorio. Una cédula sobre servicios personales y repartimientos de indios de 26 de abril de 1609 admitió los repartimientos de trabajo no sólo para las minas, sino también para labrar los campos y criar ganados. ${ }^{1 "}$ Las admitía como medidas provisionales hasta que hubiera "suficiente número de naturales o extraños que voluntariamente acudan al jornal y trabajo". El P. Diego de Torres, S.I. resumía al P. General, Claudio Aquaviva, su visión sobre los servicios personales en Tucumán y Paraguay, que podrían compararse certeramente con Cartagena:

"El servicio personal es un modo de esclavitud que en los indios impusieron contra la voluntad de los Reyes de España los conquistadores primeros, sirviéndose de ellos y de sus mujeres e hijos desde que saben andar hasta que mueren y aprovechándose de ellos en cuantos ministerios y granjerias ha podido inventar el demonio con que ha impedido el conocimiento de Dios en los cristianos".

Similares medidas gubernativas siguieron reiterándose a virreyes, gobernadores, obispos y responsables de otros niveles de gobierno, ya fuera en cédulas, ya en ordenanzas, como las de Francisco de Alfaro para el Paraguay y Río de la Plata, que en 85 capítulos acometía las relaciones hispanoindígenas. ${ }^{14}$ El 4 de julio de 1620 sendas cédulas dirigidas a la Real Audiencia del Nuevo Reino de Granada v al arzobispo de Santa Fe recordaban el cumplimiento de las órdenes dadas acerca del servicio personal de los indios,

"que estas órdenes no se ejecutan con la puntualidad y severidad que el caso requiere...porque los encomenderos y ministros españoles son personas interesadas comúnmente a su parecer en este aprovechamiento y servicio, disimulan unos a otros, de que resulta que los indios, como miserables, quedan sin defensa". ${ }^{15}$

La gravedad del problema volvía a ponerla de manifiesto el monarca al año siguiente en palabras acusadoras:

"Lastimosa cosa es lo que escribís y se dice de la gran mortandad, que ha venido por los indios de tierra caliente y cuán aprisa se van

2 Konetzke, Colección de Documentos, Vol. I I , t. 2, pp. 154-68.

13 Rubén Vargas Ugarre, S.I., Pareceres jurídicos en asuntos de Indias, Lima, C. I.P. Azángaro, 1951, p. 132.

14 Konetzke, Colección de documentos, Vol. II, t. 2, pp. 202-28.

15 Ibid, vol. II, t. 2, p. 255. 
acabando, procediendo la mayor parte de sus males y trabajos de los servicios personales que se permiten en que son culpados no solamente los encomenderos y doctrineros y principalmente las justicias que habían de mirar y procurar su defensa, sino todo género de gentes españoles, mulatos, mestizos y negros, y tanto más se hacen sentir estos daños cuanto son más escrupulosos y procedidos de omisión y descuido". ${ }^{16}$

En vísperas de suprimirse el repartimiento forzoso en Nueva España recibía el Marqués de Cerralbo otra cédula sobre los servicios personales recordando la de 1609. Como ninguna medida adoptada hasta el momento había resultado eficaz, el 14 de abril de 1633 una nueva cédula suprimía el servicio personal en que estuviesen tasados los indios, la misma que llegó al virrey del Perú, Conde de Chinchón, al gobernador Murga de Cartagena y a los demás gobernadores. ${ }^{17}$ Si en Nueva España se acabó con el repartimiento, pues se había sustituido en parte la mano de obra forzada por contratada, ${ }^{18}$ en Cartagena de Indias, Murga convocó a las máximas autoridades civiles y religiosas para que opinaran sobre el cambio de tributo.

Sobre la población de Cartagena en los comienzos de la colonización existen escasos datos, cosa nada sorprendente. Dos obispos dieron alguna información. Fr. Francisco de Benavides en 1544 habló de 40.000 indios, sin precisar si se trataba de tributarios. En 1575 Fr. Dionisio de Sanctis, O.P. se refirió a 25.000 indios en los inicios de la conquista, que habían quedado reducidos a $2.500 .{ }^{19}$

En este caso sí estaba hablando de indios tributarios, va que el obispo calculaba aproximadamente en 100.000 el total de habitantes al inicio de la conquista, pues la segunda cifra correspondía a los existentes a mediados de la década de 1570 . Consiguientemente, los 40.000 del obispo Benavides debían ser también todos los habitantes, que en la primera década habrían sufrido el choque

16 Ibid, vol. II, t. 2, p. 257.

17 Ibid, vol. II, r. 2, pp. 337-39, A.G.I. (Sevilla), Santa Fe, 39, r. 5, n. 77, R.C. al gobernador Francisco de Murga, Madrid, 14 abril 1633.

18 Gibson, Los aztecas, pp. 252-3. Jonathan 1. Israel, Razas, clases sociales y vida política en el México colonial 1610-1670, México, Fondo de Cultura Económica, 1980, p. 188. Este autor asigna un papel decisivo a la inundación del valle de México en la abolición del repartimiento agrícola.

19 Julián B. Ruiz Rivera, Las indios de Cartagena bajo la administración española en el siglo XVII Santafé de Bogotá, Archivo General de la Nación, 1996, pp. 59-60. 
biológico y sociopolítico. El visitador Melchor Pérez de Arteaga encontró en 1561 menos de 20.000 habitantes. El visitador Juan de Villabona no alcanzó a registrar ni 7.000 en 1610, y todavía en 1633 la población tributaria registrada para los partidos de Cartagena y Tolú continuó descendiendo. ${ }^{20} \mathrm{Si}$ en aproximadamente un siglo la población indígena había quedado reducida al $6 \%$, los contemporáneos no tenían más remedio que preguntarse qué estaba ocurriendo para producir tan dramático resultado.

Las causas de tan grande catástrofe quedaron recogidas reiteradamente en informes de autoridades, especialmente eclesiásticas, que una y otra vez destacaron la peculiaridad del tributo en la provincia de Cartagena, consistente en servicio personal. Así el visitador Pérez, de Arteaga confesaba: "En la segunda vista entendí en los malos tratamientos que los dichos naturales han recibido así inmediatamente en sus personas y haciendas, como en los demasiados tributos, labores y servicios personales que sus encomenderos de ellos han habido". ${ }^{21}$

Fr. Juan de Simancas, obispo de la ciudad en el tiempo de dicha visita, denunció ante el Consejo que el visitador no había suprimido el servicio personal. El obispo Fr. Antonio de Hervías dibujaba en 1589 un cuadro patético:

"los indios están casi acabados y esto por los excesivos trabajos que padecen de sus encomenderos, travéndolos ocupados de día v de noche en continuas sementeras y cosechas, y en crianzas de ganados y otros muchos servicios." 22

Por consiguiente, nada de lo planteado en la cédula de 1633 sonaba a nuevo.

\section{LA REAL CÉDULA DE 14 DE ABRIL DE 1633}

Esta cédula era la culminación de disposiciones relativas al servicio personal. En ella se pondera cómo en reiteradas ocasiones los reyes habían mandado que los indios gozaran de "entera libertad" y sirvieran como los demás vasallos. A esa libertad se interponía el servicio personal, que tantas veces se había ordenado suprimir y en su lugar imponer las tasas de los tributos en "dinero,

Ibid, pp. 60, 74 y 75.

Ibid, p. 131.

Ibid, pp. 133 y 135. 
trigo, maíz, yuca, gallinas, pescado, ropa, algodón, grana, miel y otros frutos, legumbres y especies, según el temple de la tierra". Como, a pesar de estas órdenes, aún había lugares en los que subsistía el servicio personal "a pesar de los graves daños y vejaciones de los indios, pues los encomenderos los tienen y tratan como a esclavos... por cuya causa los indios se huyen, enferman y mueren y han venido en gran disminución", después de consultarlo en el Consejo, el rey ordenaba quitar el servicio personal cualquiera fuera la forma en que existiera. ${ }^{23}$ Sin embargo, también disponía que tal medida debía tomarse con suavidad, ordenando la nueva tasa tras reunirse y consultar "con el obispo, oficiales reales, prelados de las religiones y otras personas entendidas y desinteresadas." Esta tasa sería el equivalente en valor al servicio personal que cada indio y cada encomendero conocían. En el plazo de seis meses la pondría el gobernador en ejecución, "salvo si halláredes y se os ofrecieren tan graves e inexcusables inconvenientes particulares de que acá no se tenga noticia y convenga dármela primero, que lo comencéis a ejecutar y platicar, porque sólo en este caso lo podréis suspender y sobreseer". Si quedare vacante alguna encomienda de servicio personal, no debía el gobernador adjudicarla hasta que estuviera hecha la nueva tasa. De hacer lo contrario, el gobernador sería reo ante la justicia. En la capital se recibió la cédula a mediados de agosto sin que causara ninguna conmoción, dado que el escribano de visitas Rodrigo de Zapata informó que allí no había indios tasados en servicio personal, salvo en el pueblo de Los Remedios donde cada doce indios cultivaban una fanega de maíz dos veces al año para sus encomenderos. Era la misma tasa de Cartagena. No obstante esto, el gobernador opinaba que no se podía dejar en libertad a los indios porque de ello resultarían grandes daños. ${ }^{24}$

La provincia de Cartagena entraba de lleno en los territorios donde el servicio personal aún tenía plena vigencia y no se había modificado desde su implantación. ¿Qué tenía de particular el servicio personal en Cartagena?. Tenía de particular su prolongada vigencia y su modalidad, rasgos que seguramente iban unidos por la peculiar situación geográfica. Efectivamente, al erigirse Cartagena en mercado del territorio interior neogranadino y en plaza fuerte del Caribe, donde se resguardaba la flota de galeones, se creó una demanda de suministros para embarcaciones y avituallamiento para tripulaciones, que en

23 Entre la variedad de modalidades de servicio personal no aparece la practicada en Cartagena por no afectar a ningún rubro fundamental de la producción, como era el caso de la minería del Alto Perú o de la pañería de Quito. Ver Agía, Servidumbres, pp. 59-65.

24 A.G.l. (Sevilla), Santa Fe, 21, n. 88, Sancho Girón, marqués de Sofraga, a S.M., Santa Fe, 24 agosto 1633. 
buena parte tenía que salir de la provincia. Los barcos necesitaban avituallarse para los viajes de regreso, en especial los que debían atravesar el Atlántico, aumentando con ello la demanda de los productos necesarios para tales efectos.

Una provincia de cualquier territorio secundario como Cartagena, no tenía otra forma de asegurar la producción de maíz, yuca y carne de cerdo que obligando a los indios a producirlos, mediante el cultivo de determinadas extensiones de tierra o la cría de animales, lo que comportaba exigir el pago del tributo en trabajo en lugar de especies. La ausencia de minas o de otra riqueza importante jugaba a favor de las autoridades y de los encomenderos, tanto como la blandura de carácter de los pobladores indígenas que oponían escasa resistencia.

El servicio personal se estableció por costumbre hasta que el visitador Pérez de Arteaga lo ratificó por ley a comienzos de la década de 1560: cada 20 indios sembrarían y cultivarían una fanega de sembradura de maíz dos veces al año. En 1589 el gobernador del Nuevo Reino, Dr. Antonio González elevó la exigencia, demandando una fanega por 16 indios y el visitador Juan de Villabona en 1610 todavía la subió hasta 12 indios por fanega en el partido de la ciudad de Cartagena y 10 en el de la villa de Tolú. En medio siglo, pues, Tolú vio doblarse el trabajo agrícola exigido. Había voces, posiblemente autorizadas, que consideraban ese tributo poco exigente, ya que sólo tres negros esclavos realizaban la misma tarea en estancias colindantes a los pueblos de encomienda. Posiblemente era así y se entendería que no fuese un trabajo extenuante, si los encomenderos, con el amparo de las autoridades, hubieran exigido únicamente el trabajo de rozar los cultivos. Pero no se quedaban ahí, sino que más que un trabajo personal exigían servicio personal, ocupando todo el tiempo de los indios en cuidar cerdos, cazar animales en el monte, pescar hicoteas, acarrear mercancías a los puertos, transportar leña y servir en las casas de los encomenderos. La tasa en sí no resultaba tan exigente como los servicios que encomenderos, mayordomos y aun doctrineros se arrogaban al margen de la ley. Era por consiguiente, que un hombre de leyes como Villabona juzgara posible someter a los encomenderos al imperio de la ley, eliminando los trabajos exigidos y no pagos a los indios mediante su concentración en menos pueblos bajo la tutela de los padres doctrineros y la imposición de multas. No creyó posible, sin embargo, abolir el servicio personal ya que los indios carecían de otro medio que el trabajo para pagar el tributo, aunque sí era condición imprescindible limitar los abusos por él denunciados y castigados. De modo que, todavía en el arranque de la segunda década del 
siglo XVII, un juez recto y exigente como él mantuvo el servicio personal como único medio de integrar a la población indígena en la economía de la provincia. De Villabona no puede decirse que no conociera los problemas de los pueblos porque los había visitado uno por uno.

Más no solamente los encomenderos exigieron trabajos personales sino también los mayordomos y aun los doctrineros. Cuando a los encomenderos se les prohibió residir en los pueblos de indios, tuvieron que buscar personas que no siendo encomenderos vigilaran el trabajo de los indios. Los mayordomos realizaron esa labor de supervisión y acabaron transformándose en pseudoencomenderos, porque vivían en los pueblos y podían imponer su autoridad, hasta el punto de que incluso aviaban a los encomenderos que los habían nombrado. ${ }^{25}$ El presidente González trató de poner remedio a esta situación mediante unas ordenanzas, dirigidas en gran parte contra los mayordomos.

En definitiva, una vez disminuido el poder de los mayordomos, los únicos blancos en contacto con los indios fueron los doctrineros, que por su rango espiritual estaban fuera de toda sospecha. Pero también ellos sucumbieron a la tentación de la riqueza, o al menos así se desprende de ciertos testimonios, porque también algunos de ellos se convirtieron en encomenderos de hecho, de manera que los indios soportaban toda clase de trabajos y, podríamos decir, toda clase de encomenderos. No extraña que la reiteración en las denuncias produjera la cédula de 1633 y la serie de dictámenes de las autoridades cartageneras.

1) Murga reúne la Junta sobre el servicio personal

Que todos los esfuerzos hasta entonces realizados habían resultado baldíos lo confirmaba en 1627 el obispo de la ciudad, Dr. Diego Ramírez de Cepeda, al año de haber tomado posesión del cargo con estas lúcidas palabras:

"con facilidad he entendido lo que con ellos pasa en esta tierra, informado de todos los doctrineros de ella, que en una palabra es lo que los miserables han padecido y padecen en todo el Perú con el servicio persona], que los hace de peor condición que a los esclavos". ${ }^{26}$

25 Julián B. Ruiz Rivera, «Política indigenista a fines del siglo XVI: las Ordenanzas del Dr. Antonio González», Teínas Americanistas, No. 11, (Sevilla, 1994), pp. 18-28.

26 A.G.I. (Sevilla), Santa Pe, 228, ff. 26. Obispo a S.M., Cartagena de Indias, 25 julio 1627. 
No fue casual que correspondiera al gobernador Murga convocar esta reunión como consecuencia de la cédula. ${ }^{27}$ Este gobernador había llegado en 1630 cargado de buenas intenciones y decidida voluntad de establecer la justicia, para cuyo logro no dudó en enfrentarse a los diversos estamentos de la ciudad. Mercaderes del puerto, encomenderos del interior y eclesiásticos se opusieron a los cambios que quería introducir para evitar excesos. Particularmente, en el terreno eclesiástico anatematizó a los doctrineros que se habían convertido, a su entender, en otros encomenderos so capa de religión.

Como se había denunciado con insistencia, la desaparición de los indios venía motivada por los servicios personales, la solución habría que buscarla en la erradicación de tales servicios. ¿ Había algún aspecto de la política indiana más importante que la conservación de los indios? Si la respuesta era negativa, no había duda sobre la conducta a seguir. Pero ¿quedaba claro el nexo entre régimen de trabajo personal y desaparición poblacional? Desde el punto de vista gubernativo el nexo podía estar claro y aun así no estar en condiciones de romper el vínculo de la encomienda.

El miércoles 25 de enero de 1634 se reunió en el palacio episcopal el más importante grupo de personas jamás convocado allí, la junta de Cartagena, en representación de los poderes civil y eclesiástico, una verdadera cumbre de notables en esta fortaleza del Caribe. Por el estamento eclesiástico concurrieron doce personas mientras que por el secular lo hicieron dieciséis, todas las cuales se comprometieron a expresar sus opiniones y pareceres por escrito. ${ }^{28}$

27 La catedral de Santa Fe acogió en 1565 una Junta de Notables similar con el mismo propósito de debatir el fin de los servicios personales, a la que acudieron las personas más notables. Jesús $\mathrm{M}^{\mathrm{a}}$ Porro Gutiérrez, Venero de Leiva. Gobernador y primer Presidente de la Audiencia del Nuevo Reino de Granada, Valladolid, Universidad de Valladolid, 1995, pp. 97-98.

28 La reunión contó con el gobernador, D. Prancisco de Murga, el obispo Mtro. Fr. Luis de Córdoba Ronquillo, O.S.T., el deán Dr. D. Francisco de Yarza, el teniente general Ldo. D. Francisco de Llano Velasco, el contador D. Alonso del Corral y de Toledo, el tesorero Marcos de Cortavarría, el prior del convento de Santo Domingo Fr. Agustín de Pcdraza, el guardián del convento de San Prancisco Fr. Luis de Jódar, el vicario del convento de San Agustín Fr. Justo Martínez, el vicario del Capítulo de la Merced Fr. Jerónimo de Torres, el rector de la Compañía de Jesús P. Antonio Agustín, el P. Juan de Arcos, el P. Luis Rangel, el arcediano Ldo. D. Fernando Díaz Pereira, el provisor y canónigo Dr. D Matías Suárez de Melo, el alcalde Lorenzo Ramírez de Arellano, el capitán y sargento mayor D. Antonio Maldonado y Tcjeda, el cap. D. Pedro de Altamirano, el cap. Melchor Núñez de Rozas, el castellano Matías Delgado, el regidor cap. Alonso Cuadrado Cid, el regidor cap. Diego de Rebolledo, el cap. Gregorio de Castellar, el Ldo. D. Francisco de Bctancur, el tesorero Sebastián de Alcivia, el Dr. D Fabián de Valdcs y Carrillo, el Ldo. D. Rodrigo de Oviedo y el abogado Ldo. Juan de Cuadros Peña.

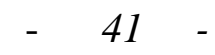


En Santa Marta, por su parte, representantes de la autoridad civil y eclesiástica celebraron diversas reuniones para acordar el criterio a seguir, que al final no fue favorable a la aplicación de la cédula. ${ }^{29}$

\section{2) Los argumentos del Obispo}

El obispo desempeñó su papel argumentando contra todas las posibles vías de contradicción al cumplimiento de la supresión del servicio personal. Como si se tratara de una relección de las aulas salmantinas, el obispo Córdoba enunció en primer lugar los inconvenientes que algunos objetaban a la tasación del tributo: $1^{\circ}$ Que faltaría el maíz y ganado de cerda para la población y para el abastecimiento de las flotas y armadas; $2^{\circ}$ Que los indios no podrían pagar a los doctrineros el estipendio que les pagaban los encomenderos; $3^{\circ}$ Que reunir a los indios en menos poblaciones tendría negativas consecuencias por las enfermedades que contraerían; $4^{\circ}$ Que sin corregidores ni alcaldes ordinarios no se podrían gobernar ni se cobraría el tributo; $5^{\circ}$ Que sin compulsión no trabajarían los indios, que eran holgazanes; y $6^{\circ}$ Que al tiempo de abonar el tributo huirían a los montes por no tener con qué pagarlo.

Suprimir el servicio personal redundaría en ventaja no sólo de las personas sino también de la producción. Para apoyar este aserto el obispo utilizó seis argumentos. De acuerdo al primero la medida propuesta era para mayor servicio de Dios, porque aliviaba el penoso trabajo de los "miserables indio; que vivían como esclavos trabajando todo el año, lo que les impedía asistir a misa y a la doctrina, así como guardar las fiestas. En segunda instancia, también era en beneficio del Rey, dado que se evitaría tener que velar porque los vasallos no padecieran graves daños por su condición de tributarios personales y, casi sin buscarlo, la nueva tributación aumentaría los ingresos del monarca. El tercer argumento afirmaba que el cumplimiento del mandato implicaba una mayor obediencia a las reales cédulas a causa de las graves penas contenidas en la última de ellas. Por el cuarto probaba que sería de mayor utilidad para la república, pues de esa manera estaría más abastecida de mantenimientos y servicios.

Aquí no tenía más remedio que expresar un argumento de autoridad porque se trataba del tema clave, el de la producción de bienes necesarios para el

29 Néstor Mesa Villalobos, Historia de la política indígena del estado español en América. Las Antillas. El Distrito de la Audiencia de Santa Fe, Santiago de Chile, Universidad de Chile, 1975, pp. 980-981 
sustento o para el abastecimiento del puerto. Contrariamente a la opinión de los encomenderos el obispo decía que la producción aumentaría porque, libres del servicio personal, los indios podrían trabajar la legua de tierra en su predio comunal, al tiempo que los encomenderos se verían forzados a buscar nuevas tierras vírgenes sin servirse de las indígenas de comunidad. El hecho de hacer trabajar a los indios en sus tierras de comunidad para pagar el tributo podía considerarse un abuso, aunque en realidad -en contradicción con la opinión del obispo- no lo era porque los indios tenían que sacar el tributo de sus recursos, ya fuera producción agrícola o pecuaria, que debían obtener en sus propios campos. La apertura de nuevas tierras, continuaba el obispo, aumentaría la producción de maíz, así como la disponibilidad de más alimentos incrementaría la cría de cerdos y con ello la actividad comercial que daría ocupación a mayor número de gentes. Los indios podrían alquilarse a otros estancieros distintos de los encomenderos, una vez que hubieran producido suficiente para sí y para el tributo. $\mathrm{Y}$ al argumento de la demanda de maíz y de carne de cerdo para las flotas y armadas, respondía el obispo, que esos productos no eran el alimento principal de las armadas, sino el bizcocho, el cazabe, la carne de vaca y los jamones, que bajaban de ja sierra, a buen seguro porque allí no podían curarse.

El quinto argumento defendía el cambio como más beneficioso para los indios, lo que no necesitaba mucho apoyo pues bastaba comparar la situación de esclavitud con la de libertad. El sexto mantenía que lejos de ser un perjuicio, redundaría en bien incluso de los encomenderos, porque a ellos no se les quitaría nada sino mantendría el valor del producto, estimando la cosecha en la media de las producidas en los últimos cinco años. El resultado de dicho cálculo fue 10 fanegas de maíz en grano por tributario al año. Para el encomendero sería una ventaja pues ya no tendría que preocuparse de si trabajaban o no, ni de si llovía o había sequía, y no correrían peligro sus conciencias a causa de las sanciones que les imponían los visitadores, como los 14.000 pesos que en ese momento tenían que abonar a los indios por excesos en el trabajo. En realidad no se cambiaba tributo por trabajo personal limitado a la roza, sino por servicio personal ilimitado.

La argumentación del prelado puede considerarse impecable y, a pesar de todo, carecer de fundamento real, porque la razón del cobro del tributo en trabajo radicaba en la producción de alimentos. Argumentaba el obispo que habría mayor producción de maíz y de carne de cerdo porque por un lado los indios seguirían produciendo las mismas cosechas en sus tierras, de modo que al producir más maíz podrían criar más cerdos y con ello fomentar el comer- 
cio y la arriería, y por otro lado, a la vez, los encomenderos se verían forzados a roturar nuevas tierras. Es un argumento lleno de lógica, pero podía fallar por la base, si los indios no estaban dispuestos a trabajar y nadie les obligaba a hacerlo. Por otro lado ¿quién iba a abrir y roturar las tierras de los encomenderos?. Porque ya no dispondrían de indios como no fuera mediante el pago de salarios. ¿Resultaría rentable el uso de esclavos en una producción de subsistencia que carecía de salida fuera del mercado local?. Y, aun pensando en la demanda portuaria, ¿habría mercado suficiente en una situación mercantil declinante como la que se vivía en aquellos años?. En este punto se pierde la objetividad de los argumentos para transformarse en opiniones subjetivas.

Sobre el estipendio -segundo inconveniente- al obispo no le cabía duda de que el encomendero debía seguir pagando un almud de maíz, como lo hacía bajo el régimen del servicio personal. Así se había establecido en un principio, pues siendo el adoctrinamiento de los indios una obligación del encomendero como contraprestación por el tributo, lo había traspasado al doctrinero haciéndose cargo de su salario. Ese arreglo no tenía un excesivo coste cuando el número de indios tributarios se elevaba a varios centenares o siquiera decenas, pero ¿cómo se resolvía cuando estos eran apenas media docena?. Ahí radicaba el problema, porque ni los indios ni el encomendero podían sufragar un doctrinero en la mayoría de los pueblos de Cartagena y, en efecto, encomenderos y tributarios habían compartido los gastos de doctrina en muchas partes.

El tercer inconveniente lo resolvía el obispo diciendo que no se moviera a los indios de sus pueblos aunque fueran pocos, dados los perjuicios que de ello se habían derivado en toda América y hubiera podido añadir el caso de Cartagena por los resultados que al respecto tuvo la visita de Villabona. De esa manera se respetaban los derechos de los indios, aunque no se resolvía el problema real de las doctrinas. Una forma de ahorrar en doctrineros era concentrar a los indios, pues de lo contrario el doctrinero debía andar itinerante de pueblo en pueblo durante algunas semanas o meses, solución poco funcional.

Con respecto al gobierno de los indios, al faltar los encomenderos para organizar el trabajo, el obispo argumentó que al igual que en otras regiones de Indias se eligieran alcaldes ordinarios entre los mismos. Al no poder negar las dificultades de este gobierno local, propuso elegir cuatro corregidores con sede en Tubará y Turbaco del partido de Cartagena, en Sanpués de Tolú y en Tacaloa de Mompox. El salario de estos corregidores saldría del que abonaban los encomenderos a los cincuenta mayordomos, según el obispo. Y la 
recogida del tributo para entregarlo a los encomenderos sería responsabilidad de los alcaldes ordinarios o de los corregidores. Tampoco podía el obispo obviar la falacia implícita en proponer que el salario de los mayordomos se pagara a los corregidores, pues si los encomenderos pagaban un salario a los mayordomos era para que obligaran a trabajar a los indios en su provecho. Si desaparecía el servicio personal sobraban los mayordomos tanto como los corregidores. De ingenuos sería pensar que iban a mantener un sueldo sin utilidad para ellos, aunque también se iban a ahorrar el gasto de herramientas, de simiente y de diezmos.

El inconveniente de que eran holgazanes y que necesitaban compulsión para trabajar lo resolvió muy precipitadamente diciendo que era un problema general en todas partes, que los corregidores o alcaldes ordinarios les obligarían a trabajar con mayor amor y caridad que los encomenderos, y que no habría riesgo de desabastecimiento, pues el propio instinto natural "obliga a todo viviente, hasta el racional, a buscar y sustentar su vida, su familia e hijos". Seguro que esto lo había oído en las aulas escolares. Habrá ocasión de contrastar esta opinión con las de doctrineros muy experimentados de la provincia.

Finalmente, los indios no necesitaban huir porque en un mes de trabajo sacarían el tributo de todo el año sin verse sometidos a la explotación constante por parte del encomendero, en lo que debían ayudar los corregidores y alcaldes para que con tiempo aseguraran el cobro del tributo de "demora". Las mujeres quedarían libres del trabajo del campo para dedicarse a la cría de cerdos y gallinas así como a la roza familiar y no se vería toda la familia, incluyendo "chinos y chinas", en una especie de cautiverio durante todo el año. El buen obispo justificaba haber prescindido de citas eruditas de las Escrituras y de los Derechos canónico y civil como recurso para ganar en claridad. En conclusión, los indios debían ser "demorados" sin dilación, pese a lo que decía la cédula de exponer antes los inconvenientes. ${ }^{30}$

\section{3) La Iglesia con su obispo}

La postura de los representantes del cabildo eclesiástico de Cartagena, de las órdenes religiosas y de sacerdotes particulares estuvo con su obispo casi uná-

30 A.G.I. (Sevilla), Santa Fe, 39, r.5, n. 77, imágenes 16-28. Parecer del Maestro Don Fray Luis de Córdoba Ronquillo, Obispo de la ciudad de Cartagena, del Consejo de S.M., 26 enero 1634. 
nimemente del lado del Rey y del Consejo en sus intentos de modificar el sistema de tributación. Dos excepciones muy reveladoras llaman la atención, las de Fr. Bartolomé de Toro y Fr. Jacinto de Herrera, doctrineros durante muchos años, que conocían los pueblos y la realidad de la población. Del cabildo podía esperarse una posición solidaria con su obispo, como lo atestiguó el deán, D. Francisco de Yarza, quien además de ponderar la injusticia de la situación de los indios, insistía sobre todo en que estos, bajo la autoridad de un corregidor, serían capaces de producir mucho más. Lo mismo opinaba el canónigo, provisor y vicario del obispado, D. Matías Suárez de Melo, quien confiaba en que habría más producción una vez que los indios fueran señores de su voluntad. Los superiores dominico, franciscano, agustino y jesuita con mayor o menor brevedad expresaron su convencimiento sobre la bondad de tasar el tributo de los indios en dinero o en especie en lugar de trabajo. El prior dominico conocía bien la situación, pues había ejercido durante una docena de años como doctrinero, lo que le facultaba para hablar sobre la incidencia del trabajo forzoso en la natalidad, sobre el régimen laboral y la distinta capacidad de los indios de sierra o de costa. Podía también recomendar que para alcalde ordinario de indios se eligiera a un individuo de fuera del pueblo. El superior franciscano ponderó la mayor capacidad de los indios sobre los negros como labradores, de forma que para producir más lo que necesitaban era libertad, porque el encomendero sacaba su plusvalía sirviéndose de los indios durante todo el año. El superior jesuita se manifestó de forma escueta partidario de la demora. La voz disonante la llevó el superior mercedario, Fr. Jerónimo de Torres, que no veía modo de producir maíz suficiente sin exigírselo en trabajo. El vicario de San Agustín comparaba el paso del servicio personal a la demora como pasar de la miserable esclavitud a la feliz libertad.

Los doctrineros precisaron como nadie los problemas del tributo y de la población indígena porque contemplaban algo más que el cobro de unos derechos tributarios. Fr. Juan Dávalos describió minuciosamente los trabajos que eran obligados a realizar, las edades a que comenzaban y la falta de salario para trabajos fuera de la tasa. Por eso razonaba que lo preferible era la tasa en trabajo personal, siempre que no les exigieran más que dicha tasa, pues una vez cumplida esta, si se les contrataba, obtendrían una remuneración por su trabajo, tendrían más incentivos, aumentarían los alimentos y bajarían los precios y hasta desaparecerían las idolatrías, que entonces les consentían con tal de tenerlos trabajando. Fr. Bartolomé de Toro se manifestó partidario de continuar con el tributo en trabajo porque no tendrían con qué obtener o reparar las herramientas -machetes, hachas o azadones- y pagar el tributo en años de 
malas cosechas. Sus mayores objeciones se centraban sobre todo en los aspectos sociales o psicológicos, como su falta de ambición $\mathrm{v}$ de codicia, su desconocimiento de oficios, su flojera para el trabajo y su propensión a la embriaguez. Claro que el mantenimiento de la tasa debía ir acompañado de una serie de medidas de los gobernadores para evitar los abusos. En una línea muy parecida el dominico Fr. Jacinto de Herrera, con una experiencia de doctrinero superior al cuarto de siglo, insistía en el carácter triste y pusilánime de los indios, en su carácter descuidado e imprevisor, en su inclinación a la ociosidad y a los abusos sexuales.

\section{4) Los hombres del gobernador}

Los civiles de la reunión, entre los que se hallaban altos cargos de la administración provincial -sargento mayor, tesorero y contador, capitanes de compañías y regidores- y otros sin cargo conocido, se inclinaron casi unánimemente por mantener la tasa a pesar de la cédula. Sólo el regidor, cap. Alonso Cuadrado Cid y el Dr. D. Fabián de Valdés, quien más adelante fue fiscal de la Audiencia de Charcas y oidor de la de Panamá, ${ }^{31}$ defendieron la voluntad del Rey como justa y bien considerada. Un detalle que no debe pasar por alto es la erudición manifestada por el sargento Francisco de Betancur y por los Ldos. Juan de Cuadros Peña y D. Rodrigo de Oviedo. A diferencia de los pareceres de los eclesiásticos, estos están llenos de citas latinas de autores de Derecho, que a decir verdad resultan complicadas y farragosas, exponentes sin duda de la ciencia del momento. De todas formas llama la atención la contraposición entre clérigos y laicos, en que no se sabe si los clérigos tenían una preparación más deficiente o si expresamente renunciaron a una exposición erudita cpe oscureciera el mensaje. Los laicos pusieron de manifiesto que con la demora no se iban a terminar los abusos, mientras que por otro lado veían muy difícil que los indios pudieran pagar en otra cosa que en trabajo. ¿Por qué pensaron así?. En primer lugar el trabajo de rozar un almud de sembradura por tributa-río era moderado, muy moderado, en comparación con el que realizaban los negros y, en segundo lugar, el tributo en dinero complicaría mucho más su vida porque tendrían que salir a ganarlo, pero ¿̇adónde?. Ponderaron hasta la saciedad que los indios eran flojos, dados a la bebida, que necesitaban quien les exigiera el trabajo, aunque al mismo tiempo pidieron que se limitara el poder de los encomenderos según las ordenanzas del visitador Villabona para

31 Ernesto Schafer, El Consejo Real Supremo de las Indias, 2 vols., Sevilla, Universidad de Sevilla v Escuela de Estudios Hispanoamericanos, 1935-47, vol. II, pp. 470 y 510. 
que no exigieran a los indios más que la tasa y para que los trabajos extras se los pagaran en dinero, no en especies. Siguieron manteniendo su idea de que los indios huirían en el momento de la paga del tributo porque no tendrían con qué satisfacerlo.

Tales eran las dos posturas fundamentales que podrían resumirse en que una estaba a favor de la libertad y la otra de la compulsión. Para los representantes de la Iglesia en general la libertad de los indios estaba por encima de cualquier otro valor, aunque saliera perjudicado el rendimiento económico. El sector civil, en el que se enmarcaban gobernantes municipales y provinciales, valoraba el bien de la colectividad o de la provincia por encima de la libertad individual, bien entendido que para ellos la colectividad la formaba una minoría pues la mayoría carecía de derechos. ¿Se hallaban los indios de Cartagena preparados para desarrollar en libertad y sin compulsión su actividad productiva?. Es el meollo de la cuestión, en el que discrepaban, aunque hay que decir que los argumentos favorables a la libertad se basaban en razones legales. Los implicados directamente en tareas de gobierno veían otro contexto más amplio de alcance civilizador por medio de un régimen de trabajo con su componente coactivo. Pese a la parcialidad de las posturas, quedan dibujados unos rasgos suficientemente claros y objetivos sobre la sociedad indígena cartagenera.

\section{5) La sociedad indígena en opinión de la Junta de 1633}

De la ciudad de Cartagena poca información se obtiene, ya que no era asunto central ni colateral de los informes. En esto se manifiesta un divorcio entre la ciudad y el interior, porque los indios no participaban en la actividad del puerto, bien porque sólo producían para los encomenderos, bien porque carecían de canales para participar en el mercado. Hay que tener en cuenta que allí los indios no eran en absoluto imprescindibles, porque existía la alternativa de los negros esclavos. Este sería el otro elemento de divorcio. Aunque con gravísimas consecuencias, se podía prescindir de los indios, pues la amenaza de desaparición esgrimida por algunos era real, no una invención. De todas las opiniones vertidas por este grupo tan selecto de personas se deduce este retrato de la región caribeña, en parte litoral, en parte fluvial y en otra interior.

\section{a) Estado de la población india}

Para 1630 la población tributaria había experimentado una transformación importante pues la originaria se había ido consumiendo hasta quedar entre 
1.000 y 1.500 tributarios -1.200 es la cifra más repetida- la población blanca había aumentado fuertemente y la negra se movía hacia arriba a impulsos de la capacidad limitada de las estancias y del trabajo urbano. ${ }^{2}$ Contando con una población indígena total de 6.000 personas y una población negra esclava y libre de similar cuantía, la ciudad estaba conformada por 20.000 habitantes sin contar forasteros ni población flotante, según el sargento mayor Antonio Maldonado de Tejeda." La provincia padecía un desarrollo desigual entre la capital, que concentraba mucha población, y el resto del territorio. Si parte de la población negra se había urbanizado, no sucedía lo mismo con la india, que permanecía sometida a un estricto control de los encomenderos a través del tributo laboral. La desproporción se manifestaba en la cantidad de pueblos que reunían escasa población'4 y se veían imposibilitados de sostener los gastos comunitarios como el de doctrinero. Los intentos de Villabona de concentrar pueblos, comentaba Gregorio de Castellar, habían llevado al fracaso, aunque mucho antes de esa fecha habían existido cantidad de pueblos que habían desaparecido y que todavía menos de un siglo antes habían llenado la campiña. ${ }^{35}$ Con todo, los intentos de Villabona no habían dado resultado y hubo que desistir de mudar a los indios de pueblo porque se morían.

La desproporción entre pobladores y pueblos derivaba del escaso número de tributarios que iban quedando, incapaces de mantener los servicios. El contador Alonso del Corral comparaba la situación de Cartagena con la de otros reinos y regiones sin vislumbrar una solución. En las regiones en que existían centenares o, al menos, decenas de tributarios por cada encomendero había forma de mantener autoridades gubernativas caciques y capitanes- judiciales -corregidor de indios- y religiosas, como el doctrinero, porque se mantenían labranzas, haciendas, ganados de donde obtener recursos. Con media docena de tributarios no había ni comunidad y bastante se haría con ampararlos para que no sufrieran excesivos abusos." ${ }^{36}$

El proceso de desaparición de los habitantes de la provincia sin duda tuvo múltiples causas aunque siempre relacionadas con la colonización, que originó el contacto de razas y el consiguiente choque biológico, así como el domi-

32 A.G.I. (Sevilla), Sania Fe, 39, r. 5, n. 77. Castellar da la cifra de 1.000 sin ningún propósito de exactitud, imag. 95, mientras el Provisor Suárez de Melo, el Sargento Mayor y el Regidor Cuadrado Cid ofrecen la de 1.200, imag. 33, 82 y 99 respectivamente. 
nio político e ideológico. Una de las más visibles formas de ese dominio fue la utilización de la mano de obra al servicio de una minoría, tal como venimos analizando en una forma muy peculiar de trabajo, como el servicio personal. Según el prior dominico las consecuencias del trabajo eran directas en la baja natalidad:

"porque el excesivo trabajo los hace que no multipliquen tanto como podrían a sus hijos y mujeres, no les faltaría el sustento ordinario y le tendrían abastecidamente, que muchas indias por el gran trabajo, si están preñadas o malparen antes de tiempo, echan las criaturas muertas, y esto es muy verosímil y se ha visto; bastantes causas son estas para que estos naturales se vayan menoscabando cada día como se ve"."

De manera palpable la estructura de la población había ido variando porque la población indígena se sustituía con esclavos, que eran mayoritarios en Tolú, pues a decir del deán, "quien abastece esta ciudad es la villa de Tolú, donde hay pocos indios que demorar, porque todos son negros esclavos con que están pobladas aquellas estancias". ${ }^{38}$

\section{b) Los bienes de los indios}

Uno de los rasgos definitorios de una sociedad es el nivel de logros materiales v la cantidad de recursos que puede atesorar. Un ejemplo evidente estaba desarrollándose en la propia ciudad de Cartagena, donde a lo largo de un siglo se habían levantado iglesias, conventos, palacios, murallas, plazas, y el puerto para negocio y disfrute de sus habitantes. ¿De qué disponían los indios en cuanto a bienes materiales?. El nivel de bienes se reducía a nada, porque prescindiendo de la choza -dado que ropa necesitaban bien poca- apenas tenían una hamaca, cuatro ollas o cántaros viejos y quizá algunas aves. No les faltaban tierras de comunidad, dado que cada vez eran menos en los pueblos, pero de poco les servía ya que no tenían tiempo para sembrar sus tierras ni criar sus ganados. El tesorero Alcivia afirmaba "que el indio no tiene bienes ningunos, muebles, ni raíces, sino meramente el fruto de su trabajo". ${ }^{39}$ Ahora bien, como no controlaba su trabajo, las ganancias no lo enriquecían a él sino a otros.

Su inserción en la economía se realizaba al nivel más elemental, a saber a través del trabajo no cualificado del campo. Fr. Juan Dávalos sintetizaba así sus ocupaciones:

Ibid, Parecer de Fr. Agustín de Pedraza, imag. 35-6.

Ibid, Parecer de D. Francisco de Yarza, imag. 30.

Ibid, Parecer del tesorero Sebastián de Alcivia, imag. 89. 
"pues siendo niños, que apenas llegan a seis o siete años, los ocupan en varios y diversos oficios como en porqueros, yerbateros y pajes... cuando son grandes y de provecho... los ocupan todo el año solamente en su utilidad y provecho haciéndoles trabajar no sólo en las rozas, que tienen obligación, sino en otras cosas como en sacar pita en gran cantidad, mucha miel, hicoteas, manteca de manatí y, finalmente, los ocupan en todas cuantas son de utilidad y provecho en la

A Fr. Bartolomé de Toro le llamaba la atención la distancia entre estos indios y los de otros distritos incluso en el trabajo agrícola, pero sobre todo en otras ocupaciones. Ponía el énfasis en la habilidad para los oficios, que allí brillaban por su ausencia,

"porque no se puede hacer consecuencia de estos indios a los de la Nueva España y Perú y Nuevo Reino de Granada y otras partes, donde están demorados a dinero, porque los de Nueva España y Perú son industriosos y hábiles como lo muestran las obras y curiosidades que de sus manos vemos y así aprenden y ejercitan oficios con que poder sustentarse y pagar sus tributos, con descanso de los del Nuevo Reino de Granada, que yo he visto también hay muchos oficiales de diferentes oficios los cuales desde las ciudades y lugares donde asisten usándolos acuden a su tiempo con sus demoras". ${ }^{41}$

Incluso en la agricultura los indios de otros sitios demostraban mayor preparación e interés por el trabajo no sólo por una psicología distinta, sino debido a un régimen laboral en el que podían obtener beneficios para sí mismos. Los indios de Cartagena por lo visto no habían tenido nunca tiempo para sus ocupaciones. ¿Por qué no se lo permitían?. ¿Simplemente por sacar de ellos el máximo provecho o porque, según decían, no sabrían trabajar sin coerción? Este es el juicio que le merecían los indios de Cartagena, al compararlos con los del Nuevo Reino de Granada, al mismo doctrinero que se ha citado anteriormente:

"De los del Nuevo Reino de Granada, que yo he visto también, hay muchos oficiales de diferentes oficios, ios cuales desde las ciudades y lugares donde asisten usándolos acuden a su tiempo con sus demo-

40 Ibid, Parecer de Fr. Juan Dávalos, imag. 55-6.

41 Ibid, Parecer de Fr. Bartolomé de Toro, imag. 61. 
ras los que están en los pueblos y repartimientos son por extremo codiciosos, inclinados a trabajar en sus estanzuelas y labranzas, que las tienen. Todos tienen bueyes con que romper y labrar la tierra, sus manaditas de ovejas con que las estercolan, caballos para sacar los frutos que cogen de ellas y llevarlos a los mercados, que en diversos pueblos se hace la lana que quitan a sus ovejuelas la hilan sus mujeres y hacen de ella mantas y camisetas, así para su uso y vestido como para venderlas, con que pagan sus demoras". ${ }^{42}$

Este fraile confirmaba la situación de atraso de los de Cartagena con respecto a los indios arriba descritos, en lo que influía sin duda el clima y factores de educación:

"pero los indios de esta tierra son tan inhábiles que no he visto ni tenido noticia de que alguno se incline a aprender un oficio ni cosa de ingenio; tan brutos como lo eran en su antigüedad; pues no saben ni tienen otra granjeria ni modo de vivir que hacer rozas para sembrar maíz y esto tan sin industria ni artificio que no hacen más que derribar los árboles de una montaña y pegarles fuego y en estando quemados hacen con la punta de un palo unos hoyos en la tierra y echan en cada uno unos granos de maíz; a ninguna otra cosa se aplican". ${ }^{43}$

El panorama no parecía muy halagüeño, pues careciendo de bienes materiales sólo contaban con el trabajo y no se inclinaban mucho hacia él ni para diversificarlo ni para mejorarlo, si bien no se les podía reprochar va que no se les permitía sacar provecho para sí mismos. Sin embargo, su desinterés no nacía de falta de condiciones, como apuntaba el guardián de San Francisco, ya "que los indios son ventajosamente mejores labradores que los negros". ${ }^{44} \mathrm{El}$ fraile agrega un componente nada desdeñable, pues a su juicio, en la pugna sobre la capacidad de indios y negros echaba en falta en los primeros la libertad, pues necesitaban "verse libres y no violentados" para rendir lo mismo que los segundos, lo que no deja de sorprender porque se les compara con esclavos. La realidad del indio manifiesta que su única riqueza era el trabajo, que tampoco controlaba libremente. Cabe concluir que la sociedad rural indígena cartagenera o bien era tan inmadura que necesitaba andaderas o bien estaba abusivamente controlada y explotada.

42 Ibid, imag. 61-2.

43 Ibid, imag. 62.

44 Ibid, Parecer de Fr. Luis de Jódar. O.F.M., imag. 42-3. 
Frente al trabajo vinculado a su encomendero ¿había otras posibilidades para los indios como trabajadores libres?, ¿qué podían hacer los indios de Cartagena que estuviera a su alcance sin un enorme esfuerzo? El fraile De Toro censuraba que los indios carecieran de interés para obtener rendimiento de las cosas que se hallaban a su disposición:

"Son tan poco o nada codiciosos que rogándoles con los patacones, como yo lo he hecho muchas veces, por cosas que ellos pueden con facilidad haber en el monte, como son bálsamo, sangre de drago, aceite de canime, cativo de mangle y otras cosas que da la tierra, algunos pájaros y animales extraordinarios que se crían en ella y se procuran y pagan para llevar a España, quieren más andarse desnudos y con las necesidades que padecen que poner un poco de diligencia y trabajo en buscarlos...con un poco de cuidado que tuvieran en criar gallinas, pudieran andar muy bien vestidos porque se las van a comprar a trueque de ropa los españoles a sus pueblos". ${ }^{45}$

Esta era de hecho la situación. ¿Debía responsabilizarse de ella al carácter indolente de la población o a la experiencia acumulada de trabajo obligatorio?

\section{c) $\dot{i}$ Tributo en trabajo o en especie?}

Cuando en 1610 el juez Villabona exigió a los encomenderos una moderación en los tributos que cobraban y les impuso fuertes multas, éstos contrataron un procurador en Madrid durante un par de años para litigar en favor de sus intereses, aunque de nada les sirvió. Montaron todo eso a pesar de que el juez no se había planteado sustituir el servicio personal por un tributo en dinero o en especie, como sería el caso en 1633. Desde la llegada de Pedro de Heredia había comenzado la utilización de la mano de obra indígena en Cartagena sin que tal situación hubiera variado, aun a sabiendas de las consecuencias que había generado. Un siglo más tarde, no ya para Cartagena únicamente con motivo del centenario, sino para todas las Indias se buscaba eliminar la obligatoriedad del trabajo. Sin ir más lejos en Nueva España se había eliminado el repartimiento de trabajo para que se produjera el tránsito hacia un mercado laboral más libre. Claro que había zonas más necesitadas de libertad y parece que una de ellas por su marginalidad era Cartagena.

45 Ibid, imag. 62. 
El primer concepto que debe quedar aclarado es el de servicio personal, que es la forma más común de referirse a la modalidad de trabajo realizado para otra persona sin remuneración. Aunque la mayoría de los participantes en la Junta de Cartagena utilizaron la expresión servicio personal e incluso el obispo la defendió expresamente como apropiada, sin embargo, algunos distinguieron para mayor exactitud entre servicio personal y trabajo personal. El provisor Suárez de Melo empleó "trabajo personal" en su parecer en lugar de servicio personal. ${ }^{46}$ El sargento mayor, por su parte, aquilató la diferencia: "el trabajo personal, que hoy hacen los indios naturales, a que algunos llaman servicio personal, no siéndolo"." Así era en el terreno legal, porque consistía en el trabajo de la roza y nada más, ya que si querían utilizar a los indios para cualquier otra finalidad, tenían que obtener permiso del gobernador y abonar el salario correspondiente.

La tributación era un campo de batalla con dos posibles escenarios. Si uno se situaba en el legal, la tasa de trabajo de una fanega de sembradura por 12 tributarios -10 en Tolú- resultaba moderada. Era el escenario elegido por el sargento mayor, el tesorero Alcivia y todos los civiles presentes en la junta. Si, por el contrario, el escenario era la realidad de los pueblos, no podía evitarse un rechazo hacia el trabajo personal. ¿Por qué?. Simplemente, porque a juicio de cualquier observador el trabajo personal, que de hecho era servicio personal sin límite, equivalía a esclavitud. Así lo expresaba el vicario de San Agustín, Fr. Juan Martínez, en su brevísimo comentario:

"pasarlos de servicio personal a pensión de demora es pasarlos de una muerte hábil a una vida racional, de miserable esclavitud a feliz libertad; tal es la vida que pasan con sus encomenderos". ${ }^{48}$

El servicio personal había dado lugar a innumerables abusos sobre los indios, tanto en el ritmo incesante de trabajo, que no les permitía tiempo para cultivar sus chacras y pegujales, como en la falta de descanso para asistir a sus deberes catequéticos y religiosos. Decía el provincial dominico:

"asisten todo el año en el trabajo de esta roza, salvo los domingos y fiestas, pues cuando han de ser instruidos y enseñados estos naturales como tan trabajados y cansados, algunos días de fiesta y domin-

46 Ibid, Parecer del provisor Matías Suárez. de Melo, imag. 33.

47 Ibid, Parecer del Sargento Mayor Maldonado de Texeda, imag. 81.

48 Ibid, Parecer de Fr. Juan Martínez, O.S.A., imag. 45. 
gos no van a Misa... se ocupan estos en trabajar para sustentarse a sí, a sus mujeres y a sus hijos, que quitarles esto será quitarles el comer". 49

A juicio de Fr. Juan Dávalos "no hay semana en todo el año que los dejen descansar aunque sea la Semana Santa."50 Pero mucho más gráficamente visualizaba esta situación con un suceso atribuido a San Luis Beltrán, que muestra el sentido del servicio personal bien que tomado del siglo XVI cuando el santo vivió y actuó en Cartagena:

"mostrando por ellos cuán injustos y malos son los trabajos tan continuos y excesivos que padecen los indios con estos servicios personales, como se ve en aquel tan celebrado del glorioso San Luis Beltrán, el cual para dar a entender a los encomenderos que por las demasías, malos tratamientos y continuos trabajos que hacían padecer a los indios comían y bebían su sangre, una vez en presencia de ellos tomando en sus santísimas manos una arepa de maíz para manifestar esta verdad apretando y estrujando la dicha arepa la convirtió toda en sangre, diciéndoles que lo que comían y bebían era el sudor y sangre de indios". ${ }^{51}$

Aunque con tres cuartos de siglo de distancia, el fraile, al igual que otros religiosos, aplicaba con propiedad aquella imagen a la realidad del momento. Su significado se mantenía ya que, según ellos, el indio era más esclavo que el esclavo negro, porque éste había costado dinero y merecía amortizarse. Así lo describía con enfáticas reiteraciones:

"el esclavo tiene el día de fiesta por suyo para oir Misa sin otro ningún cuidado, el indio no, porque le tiene por suyo no para descansar sino para trabajar aquel día en su pobre rocilla, que es de la que se ha de sustentar todo el año él y su mujer y sus hijos; mas al esclavo con particular cuidado se le da el vestido y aun la gala a los hijos de este esclavo; por el consiguiente, el sustento y aun el regalo al indio no; y, si se le da a su mujer o hijos, ¿quién se lo da o quién se lo ha de dar, si el pobre marido por la obligación de tal, cómo ni de dónde lo ha de sacar? Mas enferma el esclavo, conocida cosa es, es cuidado y solici-

49 Ibid, Parecer de Fr. Agustín de Pedraza, O.P., imag. 35.

50 Ibid, imag. 56.

51 Ibid, imag. 54. 
tado del amo ya buscándole médico, ya costeándole medicinas, va previniéndole el regalo y sustento; con el indio ¿hácese esto? No tan solamente no se hace, sino que el mayor regalo y beneficio que se hace es enviarlo a curar a su casa".32

Nada de esto admitían encomenderos o mayordomos, que resaltaban en exclusiva la ociosidad y haraganería de los indios. Como se ha puesto de manifiesto, el argumento de la compulsión se fundaba en la necesidad de aprovisionar a la ciudad de alimentos, motivo por el que encomenderos y mayordomos alegaban la grave situación de desabastecimíento que se produciría al instaurarse un tributo distinto al trabajo personal.

Para las autoridades constituía uno de ios más serios motivos de preocupación tener abastecida la ciudad y satisfecha la demanda de cuantos se acercaban al puerto, pues a pesar de que no eran los mejores momentos para Cartagena,

"ella sola en sí sin los forasteros tiene más de 20.000 personas chicas y grandes y los forasteros, que cada día entran en él, así por mar como por tierra, son muchos, con que no me parece conveniente se demoren los dichos naturales de otra manera de lo que están". ${ }^{53}$

Sin embargo, los partidarios de introducir la demora valoraban la libertad que ganarían y además los incentivos añadidos que. tendrían para producir mayores cantidades. Aunque puede que de modo un tanto voluntarista, los eclesiásticos defendieron la responsabilidad de los indios en la nueva situación. El Dr. Fabián de Valdés no creía que se produjera desabastecimiento, por lo que a su juicio ese temor no era razón suficiente para no introducir la demora. Pero aunque llegara ese caso, había 400 esclavos en las estancias para producir maíz suficiente. ${ }^{54}$ Con esta opinión coincidía el deán, cuando menos para la villa de Tolú, "porque todos son negros esclavos... y caso que fueran indios y se demorasen, no habría por eso falta de dichos mantenimientos."

Al vicario no se le ocultaba la desconfianza de muchos acerca de los indios, pese a lo cual confiaba en que la libertad los volvería más responsables: 
"que siendo señores de su voluntad con mayor cuidado acudirán a pagar el tributo y aumentar sus caudales y en contra de esto no hay más que presunción, pues no se ha hecho experiencia de ello y tengo por cierto que habrá muchos más frutos y crías de todo género que al presente por dos razones: la una que los encomenderos no han de dejar desiertas sus haciendas, sino obrarlas con negros y esclavos; y la otra, porque juzgo que obrando los indios por su libre, voluntad y en pro de sus haciendas se han de aventajar en coger los frutos". ${ }^{55}$

El deán en tono optimista y voluntarista afirmaba que con la libertad habría Dosibilidades de producir suficiente para todas las necesidades: "si el indio trabaja o le hace trabajar el corregidor lo lícito y necesario, habrá para todo". No obstante, no se dejaría totalmente a los indios a su libre albedrío sino que se les nombrarían sus autoridades naturales para cubrir el papel de los mayordomos, de modo que los vigilaran y animaran:

"si les hace trabajar el corregidor lo lícito y necesario, habrá para todo, porque cuando al encomendero le dé su encomendado cada año ocho o diez pesos y al doctrinero menos y lo mismo al corregidor, le vendrá a sobrar gran parte de su cosecha porque el corregidor le hará criar ganado y traer a esta ciudad y le hará vender la cosecha de maíz a los que tienen ganado que engordar, con que ellos tendrán para pagar y cumplir con su obligación y les sobrará para su sustento". ${ }^{5 u ́}$

Había quienes iban más lejos hasta defender que con el sistema de demora se incrementaría la producción de alimentos porque no sólo los producirían los indios sino también los encomenderos "porque, si ahora sólo dan maíz, crían y engordan ganado de cerda los encomenderos, y entonces ellos y los demás, será necesario que haya mayor abundancia en la ciudad de Cartagena". ${ }^{5 "}$ Y como argumentaba el prior dominico, se necesitaba equilibrar un poco la situación en pro del bien común, pues "con el trabajo de estos pobres indios de esta república los encomenderos solos son los que llevan el provecho, porque ellos solos son la gente que tienen el servicio; bien se infiere que no es el bien común".-""8

55 Ibid, imag. 33.

56 Ibid, imag. 31.

57 Ibid, imag. 57.

58 Ibid, imag. 38 
En las filas de la sociedad civil cartagenera no se veían los temas indios con tanto optimismo. Para algunos su situación personal o familiar condicionaba la interpretación política y social, porque pertenecían a familias encomenderas. Tanto eclesiásticos como seglares tenían una noción negativa de las capacidades de los indios. Por consiguiente, para la generalidad "pareciera justo no hacer novedad en ellas cuando se hubiesen guardado puntualmente sin sobrecargarlos con tantos excesos de la tasa, así en rozas de maíz como en otros servicios

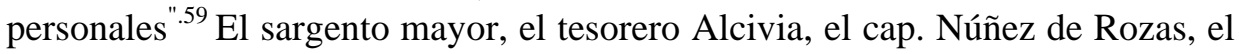
sargento Betancur, el Ldo. Oviedo y hasta los frailes Herrera y Toro se mostraron partidarios de no hacer cambios a la tasa establecida por Villabona, aunque cuidando, eso sí, que no les asignaran otras tareas y en caso de hacerlo se las retribuyeran. El conocimiento que les proporcionaba vivir sobre el terreno los problemas de las comunidades indígenas les permitía hablar con autoridad sobre los riesgos de desabastecimiento, de no poder cobrar el tributo o de disgregación de las familias, si se perturbaba el funcionamiento de las comunidades, una vez desaparecidos los trabajos personales. Contando con su natural ocioso, su inclinación a la bebida y su falta total de previsión ¿podría confiarse en que producirían suficiente para su sustento y para pagar el tributo?.

Para pagar el tributo en dinero o en especies cada indio tenía que comenzar a funcionar corno pequeño empresario independiente, que nunca lo había sido desde que se tenía memoria. Bajo el sistema de servicio personal el encomendero les proporcionaba las simientes y los machetes, hachas o azadones para el trabajo. ¿Qué ocurriría en la nueva situación?. ¿Serían capaces de obtenerlos por su cuenta, de guardar el maíz de simiente, de producir excedentes y llevarlos al mercado para obtener dinero con que comprar las herramientas?. Los dos doctrineros que dieron su juicio más extenso y ponderado no los creían capaces de acoplarse a la situación del nuevo tributo. No era cuestión de negarles la libertad, sino de enseñarles mediante alguna coerción. ¿Convenía educarlos usando la compulsión o sólo aprenderían en total libertad?. Ahí estaba el punto de discrepancia.

\section{d) Sociedad y gobierno indígenas}

Los escasos rasgos que se traslucen de los pareceres emitidos por los miembros de esta Junta revelan una sociedad rural sumamente dependiente, sin resortes propios de funcionamiento, quizá porque nunca los habían ejercitado. El dominio que los encomenderos ejercían a través de los mayordomos

59 Ibid, imag. 70 
era absoluto, ya que dominaban el tiempo disponible de los habitantes. No se habla nunca de autoridades indígenas salvo en el caso de elegir corregidor o alcalde indígena, aunque contaban con sus caciques y capitanes. El corregidor debería presidir una provincia o un partido, como en el Perú, mientras el alcalde sólo tendría autoridad local sobre su pueblo. En el caso de decidirse por alcaldes indios se esperaba que éstos tratarían a los indios con más afecto, aunque se proponía tener la precaución de elegir esos alcaldes entre personas de pueblos distintos al propio por evitar favoritismos de familia:

"pero advierto y digo que el tal alcalde ha de ser entresacado y escogido de otro pueblo circunvecino y no natural del dicho pueblo para que para esta justificación y trabajo no le lleve el amor del padre, hermano o pariente. ${ }^{60}$

La sociedad rural cartagenera estaba de tal manera estructurada que no podía tener autogobierno porque no se reconocía ninguna independencia. Si esto era aplicable a no pocos territorios indianos, en Cartagena era especialmente así por la desigualdad tan enorme entre los de arriba y los de abajo, o como lo expresaba Fr. Luis de Jódar, "que por bien de un particular se haga esclavos a muchos que son de naturaleza libre"61 Es el juicio más repetido: "los encomenderos tienen y tratan a los indios como a esclavos y aun peor", al. decir de Fr. Juan Dávalos. ${ }^{62}$ En esas condiciones y con el especial desarrollo que el tributo había tenido en Cartagena no podía existir sociedad indígena. Tampoco se podía pedir a los indios que tuvieran un sentido de comunidad y de solidaridad frente a sus explotadores blancos porque ese desarrollo no les correspondía. Uno de los resortes, según nuestra mentalidad, que hubiera sido asociarse y juntarse en pueblos mayores, no era compatible con la idiosincrasia indígena, que se oponía a abandonar sus lugares, sus tierras, su paisaje, sus árboles, sus peñas, sus arroyos y sus dioses naturales. Ya se había demostrado durante la visita de Villabona que en los nuevos lugares donde se les ubicó acabaron en peleas entre comunidades de distinta procedencia. $^{63}$

Por consiguiente, faltos de libertad y sometidos a esclavitud, los indígenas no habían alcanzado ningún avance en su organización. Por eso conseguir el cambio del tributo se equiparaba a obtener la libertad, mientras lo que estaba

60 Ibid, imag. 40.

61 Ibid, imag. 44.

62 Ibid, imag. 54.

63 Julián B. Ruiz Rivera, «El juez Villabona frente a la oligarquía encomendera de Cartagena», Anuario de Estudios Americanos, Vol. LII, t. 1, Sevilla, 1995, pp. 107-9. 
sucediendo provenía del desánimo de seguir reproduciéndose y de seguir conviviendo en los pueblos. ${ }^{64} \mathrm{~A}$ eso podían añadirse malos tratos de los encomenderos o mayordomos, como el caso que describía Fr. Juan Dávalos:

"y aún aquí estoy escribiendo estos renglones y tengo presentes dos indios bien apaleados y azotados, llorando y pidiéndome favor que los defienda de la furia de los mayordomos y siempre es así sin que en ello pueda haber alguna esperanza de remedio"65

Se podía suponer la consecuencia de todo esto en la fuga de sus pueblos, que en alguna ocasión se apunta, aunque no fuera la conducta más común:

"no gozan de la libertad que según Cristianos deben gozar y tener, por lo cual como vejados y oprimidos desamparan sus tierras y se van a vivir a extrañas, dejando sus mujeres e hijos y huyendo de una dura servidumbre, que es más que esclavitud". ${ }^{66}$

El provisor solicitaba al monarca el cumplimiento de las leyes y que "sean libres del trabajo personal, como lo son sus vasallos en España".

\section{e) Religión y cultura}

Cualquier juicio que se hiciera sobre el grado de aprovechamiento de los indios estaría condicionado por la situación de atraso a la que se les tenía sometidos. Muchos se habían admirado de la facilidad de los indios para aprender la lengua castellana de tal manera que estaban casi completamente asimilados. Nuestro informante dominico, que tenía a sus espaldas una larga experiencia de doctrinero, atribuía ventaja a los indios cartageneros en comparación con los del altiplano:

"que es diferente capacidad la de aquellos indios que la de estos, respondo que más capaces son estos que los del Reino y vemos que algunos saben leer y escribir, saben cantar canto de órgano, tañer y tocar chirimías y trabajar en sus mismas tierras, tanto que ellos solos pueden abastecer como abastecen la ciudad". ${ }^{67}$

64 A.G.I.. ( Sevilla), Santa Fe, 39, r. 5, n. 77, imag. 35-6.

65 Ibid, imag. 54.

66 Ibid, imag. 35.

67 Ibid, imag 40. 
Simultáneamente, otro fraile ponderaba lo inhábiles que eran los indios que carecían de interés por aprender cualquier oficio. ¿Con qué podemos quedarnos?. Puede que no fueran contradictorios ni incompatibles esos dos aspectos pues aunque no se interesaran por el trabajo, puede que les atrajera la cultura, la lengua y la música.

Todavía era más milagroso haber alcanzado esos logros estando, como estaban, siempre ocupados en trabajos ajenos y sin poder siquiera asistir a la doctrina ni a la Misa dominical ni celebrar la Semana Santa. ${ }^{68}$ Incluso se acusó a los encomenderos y mayordomos de hacer la vista gorda a las idolatrías indígenas siempre que, a cambio, no se olvidaran de llegar al trabajo, pues "el mayordomo no mira si idolatran o no, sino sólo en que los indios acudan al trabajo del encomendero". ${ }^{69}$ Así que entre el limitado número de doctrineros, la dispersión de los pueblos y estos otros factores el nivel de instrucción religiosa dejaba que desear. Aun en los lugares en que asistía permanentemente el doctrinero, enseñaba la doctrina y administraba los Sacramentos, "no hay indio que en su casa tenga una imagen de Nuestro Señor ni de su benditísima Madre, ni una Cruz de palo siendo tan fácil hacerla". ${ }^{70}$

La sociedad rural carecía de autoridades efectivas para contrarrestar el poder de los encomenderos y mayordomos. Ya que ésta giraba en torno a los vínculos de familias y de clanes, enraizados en su terruño se hallaban faltos de capacidad para superar esos límites, de modo que, al menos por la experiencia acumulada, todo lo foráneo era visto como una amenaza. Con respecto a sí mismos, sus móviles eran básicos y primarios, generalmente orientados a la satisfacción de las necesidades básicas. Civiles y religiosos, con la excepción de Fr. Agustín de Pedraza, les achacaban su inclinación al ocio y la haraganería. Para ese dominico no había tal condición ya que desde los 17 años y aun antes no hacían otra cosa que trabajar. Cuando huían al bosque, donde tenían posibilidades de extraer productos para el mercado, como pita, cativo de mangle y otras gomas y resinas, solo buscaban comer y dormir, viviendo completamente desnudos. $^{71}$

En todo ese comportamiento influía su psicología falta de ambición y de codicia, que no les impulsaba a aprender nada nuevo sino sólo a conservar sus tradiciones. Con toda seguridad parte de esa tradición sí era el consumo de

68 Ibid, imag. 56.

69 Ibid, imag. 58.

70 Ibid, imag. 68.

71 Ibid, imag. 63. 
chicha hasta el punto de poner en peligro la subsistencia de la familia porque apenas cogida la cosecha de maíz y antes que se hubiera secado, si se descuidaban las mujeres, los hombres la convertín en chicha y se la bebían. La bebida era más que una evasión o un vicio, era todo un rito para cualquier situación vital. Así lo expresaba el fraile de Toro:

"Son con esto tan inclinados a la embriaguez que toda su felicidad, sus bodas, sus fiestas y regocijos los cifran y libran en embriagarse; con eso celebran sus regocijos y lloran sus muertos $y$, finalmente, este es su regalo y así a sus mujeres las ocupan toda la semana en hacer chicha, que es su bebida para embriagarse el domingo, en que gastan todo el día y la noche y gastaran todo el año, si los dejaran, cometiendo mil maldades, como gente que está fuera de sentido".'2

No sorprende su talante descuidado e imprevisor porque vivían demasiado al día, sin alcanzar la trascendencia de unas responsabilidades que comprendieran siquiera a la familia, como relata el dominico Herrera:

"estándoles doctrinando y viendo en ellos el descuido tan grande que tienen en las cosas de su sustento en la crianza de sus hijos, en el poco amor que tienen a sus mujeres, reprendiéndoles lo poco que miran por ellos, se ríen y me han respondido que si su mujer se muriese casarán con otra y si su hijo se muriese tendrán otros hijos". ${ }^{73}$

Sus normas morales relativas al comportamiento sexual distaban de ser exigentes, antes al contrario daban lugar a situaciones de promiscuidad que debían tener hasta consecuencias biológicas. Así las describía el citado dominico:

"son amiguísimos de la ociosidad, de donde sobrevienen grandísimos pecados, particularmente siempre están embriagados $\mathrm{v}$ estándolo cometen gravísimos incestos con madres, hijas, hermanas, cuñadas, tías, sobrinas, sin reparar en ninguna manera en ley divina $v$ humana". ${ }^{74}$

72 Ibid, imag. 63.

73 Ibid, imag. 68.

74 Ibid, imag. 68. 


\section{REFLEXIÓN FINAL}

El gobernador Murga siguió todos los pasos explicados en la cédula, pues al no tener claro que pudiera cumplirse, reunió la junta. Como era evidente que no había unidad de criterio y ni siquiera una división estricta entre eclesiásticos y seculares, decidió suspender la ejecución:

"porque siento que el hacer novedad con los indios de esta Provincia ha de ser su total ruina, sin que de ello les resulte útil alguno, porque la demora que hoy tienen es una tasa muy justificada y, si se redujese a dinero habiéndoles de cargar los estipendios de doctrina y demás gastos y reconocimiento que es fuerza se apliquen a sus encomenderos, siendo como son la mayor parte de las encomiendas de nueve y diez indios, y que ninguna hay capaz para esta conmutación, tengo por imposible que lo puedan pagar". ${ }^{75}$

Por encima de todos los argumentos filosóficos y teológicos, de derecho divino $\mathrm{v}$ de gentes, el gobernador impuso su ley, no de manera caprichosa, sino ponderada. La razón: eran demasiado pobres las encomiendas de Cartagena para sufragar los gastos mínimos. Pudo haber llegado a las últimas consecuencias, es decir, a la misma conclusión que el juez Villabona, quien al final recomendó acabar con el sistema de encomiendas ${ }^{76}$ Claro que no atendieron su recomendación. Murga tuvo en cuenta la experiencia de Villabona, tanto para no suprimir el trabajo personal como para, al final, no concentrar los pueblos. Para el gobernador Murga el cambio de tributo no se podía ejecutar, más aún, se debía mantener la tasa, aunque el protector tendría que vigilar el buen trato a los indios y el gobernador el cobro de los excesos de trabajo, como lo estaba haciendo él con los encomenderos al exigirles multas.

La realidad se imponía. Si se les ponía un tributo en dinero ¿adónde iban a ir a buscarlo?. Pero aunque no fuera en dinero, sino en especies, ¿cómo podrían tan pocos indios pagar tributo, doctrina y los demás gastos?. A cada indio le iba a salir por el doble de la tasa en trabajo personal. La paradoja consistía en que también el gobernador tenía razón en principio, porque de hecho la tasa de tributo en trabajo no tenía límite. Lo cierto es que aunque la demora no se implantó en Cartagena, la Junta celebrada en 1633 con todo el debate subsiguiente no resultó estéril. De momento no hay más prueba que la evolución,

75 A.G.I. (Sevilla), Santa Fe, 39, r. 5, n. 77, imag. 1-2. Gobernador Fco. de Murga a S.M., Cartagena de Indias, 24 agosto 1634.

76 Ruiz Rivera, Los Indios de Cartagena, p. 26. 
a largo plazo, de la población indígena, la cual ya en la segunda mitad del siglo inició su recuperación. ${ }^{77}$ La tendencia a su desaparición se invirtió porque jueces y personas letradas contribuyeron a crear un clima de oposición, como en esta importante discusión sobre el servicio personal.

Más allá del suceso de la Junta sus miembros pudieron haberse preguntado, como lo había hecho el juez Villabona dos décadas antes, si la encomienda se justificaba, es decir, si debía seguir existiendo. Si la encomienda no era posible sin el servicio personal y el servicio personal originaba tantos perjuicios ¿por qué no acabar con la encomienda misma y erradicar así el servicio personal?. Los tiempos no eran propicios para tales cambios, dadas las dificultades de la monarquía y del territorio peninsular. Como en tantas otras ocasiones se adoptó una vía intermedia, que no satisfizo a los más exigentes, pero siguió insistiendo en la necesidad de justicia dentro del sistema de tributación, que en sí mismo era desequilibrado e injusto.

77 Ibid, pp. 73-7. 